The suture holding the free end of the ileum in the lumen of the colon is now withdrawn and the needle puncture in the anterior wall of the colon closed by a purse-string Lembert suture.

\section{Stage 3}

The incision in the abdominal wall is closed in layers by continuous catgut sutures, and the skin by interrupted silkworm-gut sutures or Michell's clips. If the rectus muscle has been divided the posterior and anterior walls of its sheath are closed by continuous catgut sutures: the muscle itself is not stitched and tension sutures are unnecessary.

\section{Comments}

The advantages of the transverse abdominal and of the electro-surgical incision have been fully described elsewhere (Moore, 1922 ; 1940). As only two clamps are used to control the intestinal contents, tissue trauma is largely avoided. The transverse incision affords free and adequate exposure of the peritoneal cavity.

The peristaltic action of the ileum and the colon being similar, the passage of the contents is not adversely affected, and this diminishes the possibility of regurgitation and of the development of ileus.

Leakage does not occur at the anastomotic line, for the greater the pressure of the contents of the ileum the tighter the union. The peristaltic waves travelling in the same direction still further lessen the risk of leakage and regurgitation.

Results have fully justified the operation both in the method of approach and in the reconstruction of the alimentary canal. Most prominent of the beneficial effects observed were the early passage of flatus, the absence of marked abdominal distension, the early return of normal peristalsis, the absence of ileus, the diminution of postoperative sickness and vomiting, and the early restoration of normal appetite.

When the operation was performed in the treatment of faecal fistula, but especially that of the ileo-caecal variety, early and permanent closure of the fistula resulted. In cases of colonic obstruction post-operative comfort was notable. The patient was saved the embarrassing discomfort of colostomy, and a second operation could be performed in a clean field.

\section{Conclusion}

Maylard made use of the axiom that "there is nothing new under the sun" when it was mentioned that the transverse abdominal incision had been practised by Paulus Aegineta of Alexandria. It is possible that future research may reveal that this method of anastomosis was practised at an equally early date, but it was undoubtedly originated in this country by Maylard of Glasgow in the early part of the present century.

We were Maylard's assistants. That we assisted him with the operation on many occasions refutes any modern claim to priority. Sonnenburg undoubtedly performed the operation in Berlin some years earlier, as was stated by Professor Macfarlane, whom we also assisted. The credit for this excellent operation must be awarded to Sonnenburg and to Maylard, who, working independently and unknown to each other, devised the method in Germany and in Great Britain respectively. Apart from the substitution of the active electrode for the scalpel there has been no modification of the original technique.

\section{REFERENCES}

Bickham, W. S. (1924). Operative Surgery, Vol. 4. Saunders, Philadelphia. Da-Costa, J. C. (1931). Modern Surgery, General and Operative, p. 1027. Saunders, Philadelphia.

Kimbarovskij, M. A. (1951). Abstracts of World Surgery, Obstetrics and Gynaecology, Vol. 9. No. 4: Abstract 697, p. 191.

Maylard, A. E. (1913). The Practice and Problem in Abdominal Surgery. London.

Moore, W. J. (1922). Ann. Surg., 75, 70.

- (1940). Med. Press. 204, 304.

\section{PENTA-ERYTHRITOL TETRANITRATE IN TREATMENT OF ANGINA}

\author{
BY
}

DAVID WEITZMAN, M.D., M.R.C.P.

Senior Registrar, Institute of Cardiology, National Heart Hospital

Penta-erythritol tetranitrate* (P.E.T.N.) is said to be a vasodilator with a prolonged action. It was first used in Sweden during the recent war, when erythritol tetranitrate, which has a similar action, became unobtainable. Subsequently it has been used in France and the United States.

The chemical properties of P.E.T.N. have been described by Van Oettingen et al. (1944). At that time this substance, in use as an explosive, was investigated for any harmful effects on its handlers. Its composition is shown by the formula<smiles>COOCC(CO[N+](=O)[O-])(OOC)OOC</smiles>

It is more stable than glyceryl trinitrate and erythritol tetranitrate, and liberates nitrite more slowly than either of these. Absorption from the alimentary tract is slow in animals. In two human volunteers an insignificant rise only was found in blood nitrite up to three hours after the oral administration of $64 \mathrm{mg}$. No longterm toxicity was noted in animals given P.E.T.N. for one year.

Marche (1950) states that P.E.T.N. acts more strongly on the coronary vessels than on the peripheral circulation; the effect starts 10 minutes after ingestion, and the protective action against angina persists for four to five hours.

Bjerlov (1943) found that the effects of P.E.T.N. in 165 cases were as good as, or better than, those of erythritol tetranitrate. The dose used varied from 45 to $180 \mathrm{mg}$. daily. Headache appears to have been the most troublesome side-effect. Balatre et al. (1949) treated 24 cases, with marked improvement in 12 and moderate improvement in nine. In their series a fall in blood pressure was often seen, and was greater in hypertensive patients. Dailheu-Geoffroy (1950) reported 10 excellent and 69 moderate responses out of 97 cases.

Winsor and Humphreys (1952) gave P.E.T.N. to 125 cases of angina and 125 patients with pain from other causes-arthritis, gall-stones, etc. They found improvement in $78.4 \%$ of the anginal patients as compared with $4 \%$ of the others. The dose ranged from 10 to $70 \mathrm{mg}$. daily, averaging $30 \mathrm{mg}$. (10 mg. thrice daily). Higher doses brought no greater improvement and increased the liability to side-effects (headache, nausea, skin rashes). In three patients with acute coronary insufficiency the resting E.C.G. returned to normal.

Plotz (1952) used $10 \mathrm{mg}$. three times a day with the occasional addition of $10 \mathrm{mg}$. at night. He too found that larger doses were not well tolerated. Of 39 cases, 29 were improved (including five in status anginosus), but only four were able completely to discontinue gly-

*The tablets of penta-erythritol tetranitrate used in this investigation were kindly supplied by Bayer Products Ltd., under the name of " mycardol." 
ceryl trinitrate. No effect was observed in four patients with cardiac infarction. Talley et al. (1952) were not impressed with the effects of P.E.T.N. as compared with a placebo in 14 patients. Perlman (1952) and Samuels and Padernacht (1952) report favourably on the use of P.E.T.N. in peripheral vascular disease.

\section{Materials and Methods}

A clinical trial of P.E.T.N. has been carried out on 65 cases with angina pectoris. The series comprised 54 males and 11 females; their ages ranged from 36 to 74 , and averaged 56. The diagnosis of angina pectoris was unquestionable in all. In 37 the resting E.C.G. showed evidence of cardiac ischaemia. In three others there was bundle-branch block, and eight patients with normal resting E.C.G.s showed ischaemic changes after exercise. In the remainder the history was classical.

The cases were graded according to their severity as follows:

Grade I: pain only on strenuous effort ( 2 cases).

Grade II : pain on going uphill, or hurrying, or on walking after a meal or in the cold (27 cases).

Grade III, pain on walking at ordinary pace on the flat (30 cases).

Grade IV: pain on walking at ordinary pace on the flat, in less than 100 yards (6 cases).

Grade V: acute coronary insufficiency-that is, pain at rest and/or on the slightest activity.

Two other grades -0 , indicating remission of pain, and VI, denoting fresh cardiac infarction-were also used in the assessment of progress. Only patients whose effort tolerance had remained unaltered for six months or more were included in the trial. Evidence of positive response to the drug was provided by an increase in effort tolerance, so that the case moved into a better grade, or by a decrease in the pain brought on by the same amount of effort.

Tablets containing $30 \mathrm{mg}$. of P.E.T.N. were used, dummies identical in appearance and taste with these being also supplied for control purposes. Each patient was instructed to swallow two tablets three times daily, at regular intervals. In some cases this dose was later increased. Thirty-four patients were given P.E.T.N. and 31 had dummy tablets. Approximately $50 \%$ of the patients in each effort grade were put into each group. After two to three months 15 patients whose condition remained unaltered while taking dummy tablets had P.E.T.N. substituted without their knowledge. Another group of 15 patients, who were apparently improved while taking P.E.T.N. were switched to dummy tablets or had their P.E.T.N. tablets discontinued. In most cases the results were assessed after a period of not less than three months; in nine cases treatment with P.E.T.N. was maintained for longer periods in order to determine the development of any tolerance or of long-term

TABLE I.-Results

\begin{tabular}{|c|c|c|c|c|}
\hline & $\begin{array}{c}\text { Cases } \\
\text { Treated } \\
\text { Primarily } \\
\text { with } \\
\text { P.E.T.N. }\end{array}$ & $\begin{array}{c}\text { Cases Treated } \\
\text { with P.E.T.N. } \\
\text { after Serving } \\
\text { as Controls } \\
\text { without } \\
\text { Change } \\
\end{array}$ & $\begin{array}{c}\text { Total } \\
\text { Results } \\
\text { in All } \\
\text { Treated } \\
\text { Cases }\end{array}$ & $\begin{array}{l}\text { Control } \\
\text { Group }\end{array}$ \\
\hline $\begin{array}{l}\text { Effort grading improved } \\
\text { Pain less severe and or } \\
\text { less glyceryl trinitrate } \\
\text { needed } \quad . \\
\text { No change } \ldots \\
\text { Pain more severe, or less } \\
\text { effort possible, or fur- } \\
\text { ther ischaemic E.C.G. } \\
\text { changes } \\
\text { Treatment discontinued } \\
\text { because of side-effects }\end{array}$ & $\begin{array}{r}8(24 \%) \\
6(17 \%) \\
11(33 \%) \\
6 *(17 \%) \\
3(9 \%)\end{array}$ & $\begin{array}{l}1 \quad(7 \%) \\
2(14 \%) \\
11(73 \%) \\
1(7 \%) \\
0\end{array}$ & $\begin{array}{r}9(18 \%) \\
8(17 \%) \\
22(44 \%) \\
7 *(15 \%) \\
3(6 \%) \\
\end{array}$ & $\begin{array}{r}3(10 \%) \\
3(10 \%) \\
23(74 \%) \\
2(6 \%) \\
0\end{array}$ \\
\hline Total & 34 & 15 & 49 & 31 \\
\hline
\end{tabular}

* One of these patients died of fresh occlusion, but this did not occur until two months after discontinuing treatment. toxic manifestations. All patients had glyceryl trinitrate if an attack of pain occurred. The results are shown in Table I.

In addition, two in-patients with acute coronary insufficiency were given P.E.T.N. for short periods without any apparent effect on their progress. In a third case in this group P.E.T.N. was shown to influence effort changes in the E.C.G. (See Fig.).

Dosage.-The dose was $60 \mathrm{mg}$. thrice daily in most cases, but in 9 patients who failed to show improvement it was increased to $60 \mathrm{mg}$. four times a day. This resulted in some relief in two cases. A further increase to a daily total of $300 \mathrm{mg}$. proved intolerable, because of side-effects, in all but one case. This patient has been able to tolerate $360 \mathrm{mg}$. daily for over six months, with definite improvement in effort tolerance.

Side-effects.-Undesirable side-effects were experienced by eight patients. They comprised lethargy (often with a sense of depression) in five, digestive upset in three, headache in two, and visual disturbance in one. In three of the cases these side-effects resulted from the routine daily dose of $180 \mathrm{mg}$. and were troublesome enough to necessitate withholding the drug. In one of these patients toxic symptoms reappeared when treatment was recommenced with only $90 \mathrm{mg}$. daily. In the remainder side-effects were seen only with higher doses. No long-term toxic effects have been observed in 10 patients who have taken the drug for periods of six months up to one year, and no diminution of effectiveness has been seen in these cases.

\section{P.E.T.N. and the Electrocardiogram}

The effect of P.E.T.N. on the electrocardiogram was studied in six cases. In three of these the ST segment depression induced by effort was abolished by oral ingestion of $120 \mathrm{mg}$. of P.E.T.N. The illustration shows how this effect is present 15 minutes after taking the drug. It is seen to persist for four hours but not for five.

There was a definite relationship between E.C.G. patterns and response to P.E.T.N. in the 46 cases in which treatment was maintained (Table II). Thus of 30 cases with

TABLE II

\begin{tabular}{|c|c|c|}
\hline E.C.G. & $\begin{array}{c}\text { No. of } \\
\text { Patients }\end{array}$ & $\begin{array}{l}\text { No. Improved } \\
\text { (Effort More } \\
\text { or Pain Less) }\end{array}$ \\
\hline 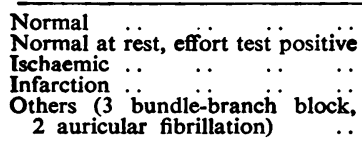 & $\begin{array}{r}11 \\
3 \\
11 \\
16 \\
5\end{array}$ & $\begin{array}{l}3 \\
1 \\
6 \\
7 \\
0\end{array}$ \\
\hline
\end{tabular}

electrocardiographic proof of coronary disease, $14(48 \%)$ responded to P.E.T.N. as compared with 3 out of $16(19 \%)$ without such proof. It therefore seems that the more severe the ischaemia the more likely is the case to benefit from P.E.T.N. Winsor and Humphreys (1952) state that the worst cases show the greatest improvement. However, in the present series there was no correlation between severity of symptoms and response to the drug.

The E.C.G. was repeated in 12 patients under treatment with P.E.T.N. In one it was found to have reverted to normal; in two others the ST depression after exercise was abolished or lessened; in five there was no change ; and in four the E.C.G. showed deterioration.

\section{Effect on Blood Pressure}

Casual readings were made in the out-patient department two to four hours after the last dose. In no case was there any significant fall in pressure. Other authors have described definite hypotensive effects from P.E.T.N. Thus Bjerlov (1942), after $30 \mathrm{mg}$., found a fall of from 10 to $45 \mathrm{~mm}$., lasting two to five hours in 10 patients; Balatre 
RESTING

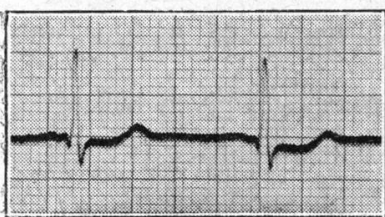

BEFORE P.E.T.N.
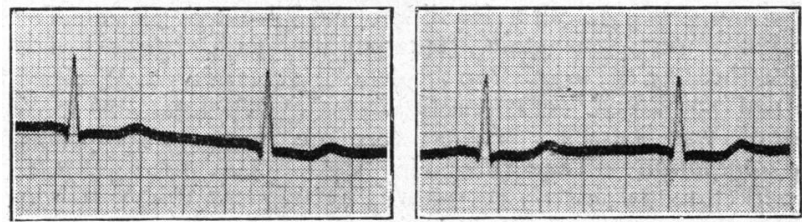

15 Minutes AFter P.E.T.N.
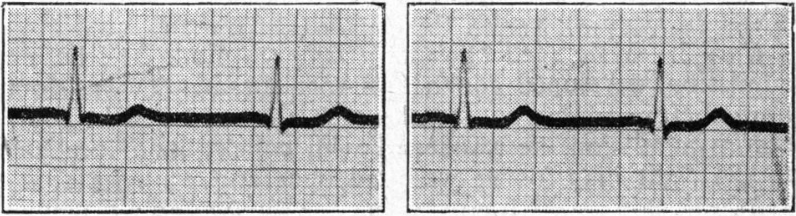

1 HOUR AFter P.E.T.N.
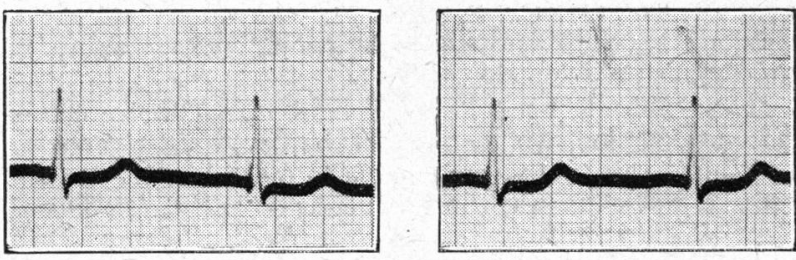

4 HOURS AFTER P.E.T.N.
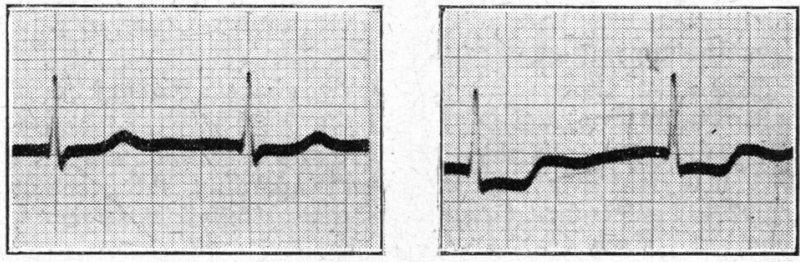

5 HOURS AFTER P.E.T.N.

Electrocardiographic record (Lead V5) before and after taking P.E.T.N.

et al. (1949) state that $20 \mathrm{mg}$. can provoke a fall of 30$35 \mathrm{~mm}$. in the systolic and $15-20 \mathrm{~mm}$. in the diastolic pressure in man. This was not confirmed in the present series, nor was there any significant fall in basal pressures measured over three hours in two normal subjects after taking $60 \mathrm{mg}$. These findings are in agreement with those of Plotz (1952), who found no notable fall in 35 cases.

Other Conditions.-The series included two cases with syphilitic aortic incompetence and one with rheumatic valvular disease. In these, P.E.T.N. had no effect on effort pain.

\section{Discussion}

One may regard the improvement that occurred on dummy tablets as indicating the extent to which natural amelioration and psychological factors affect results. Taking this into consideration, the improvement rate is significantly greater in the treated group. Furthermore, it was shown that P.E.T.N. could abolish electrocardiographic changes due to effort, and that this effect could persist for four hours. Winsor and Humphreys (1952) have demonstrated the same phenomenon.

It was therefore rather surprising that the response was so poor in the 15 patients who were given P.E.T.N. after a period on dummy tablets, as compared with the group primarily treated with P.E.T.N. Since this finding cast doubt on the validity of the results, a further check was made in another 15 patients who had improved with P.E.T.N. In seven all tablets were stopped, and in five of these the symptoms returned to their previous severity; but no deterioration was noted in five out of eight cases in which dummy tablets were substituted for P.E.T.N.

This finding detracts still more from the significance of the results. However, another explanation is worth considering. It is possible that the maintenance of improvement in the treated patients subsequently given dummy tablets was the result of an increase in collateral circulation induced by P.E.T.N. Zoll and Norman (1952) have shown that sodium nitrite stimulates the development of anastomotic vessels in the pig's heart after experimental coronary occlusion: a significant increase in collaterals is seen after as little as two days' treatment. There is, however, no direct proof that P.E.T.N. does cause any increase in the number of coronary anastomoses in man; and the finding, already stated, of progressive ischaemic change in the E.C.G.s of four cases under treatment shows that any such effect is not invariable.

The evidence is thus seen to be inconclusive, and further study would appear to be indicated. The results obtained by direct comparison of the two primary groups in the trial show a significantly greater improvement rate in the treated cases. The subsidiary studies throw doubt on this finding. Nevertheless, unquestionable and sustained improvement in effort tolerance was observed in about one-fifth of the treated cases, and some symptomatic relief in a like number. Objective evidence of improvement in coronary blood flow has also been furnished by effort tests.

\section{Conclusions}

P.E.T.N. would appear to have a place in the treatment of cardiac pain. In a small number of cases its routine prophylactic administration may replace the necessity for glyceryl trinitrate. Patients whose sleep is disturbed by nocturnal angina may benefit from a dose of P.E.T.N. taken before retiring. If patients find that routine P.E.T.N. diminishes but does not obviate the need to take glyceryl trinitrate for anginal attacks, there is probably little purpose in their taking two drugs rather than one. An exception to this is the case in which angina is most troublesome on first rising. Such patients often find that a tablet of glyceryl trinitrate chewed first thing may enable them to dress and get to work without pain. In such cases the combination of early morning glyceryl trinitrate with routinely spaced doses of P.E.T.N. may result in almost complete freedom from anginal attacks. P.E.T.N. seems to have little or no influence on acute episodes of increasing ischaemia.

\section{Summary}

Penta-erythritol tetranitrate (P.E.T.N.) is an antianginal drug with a prolonged action, lasting up to four hours after administration. This effect has been confirmed by electrocardiographic studies.

Forty-nine patients have been treated with this substance for several months. The usual dose employed was $60 \mathrm{mg}$. thrice daily. In nine patients effort tolerance was improved, and a further eight patients noticed diminution in the number and severity of anginal attacks.

This response was significantly greater than that of a control group taking dummy tablets; but the results after substituting drug for dummy, and vice versa, were not entirely in keeping with the original findings.

The use of P.E.T.N. for preventing angina is of value in some patients, but seldom replaces the need for glyceryl trinitrate.

This investigation was undertaken at the instigation of Dr. Paul Wood, Director of the Institute of Cardiology, and the majority 
of the patients were under his care. I would like to express my gratitude for his advice and encouragement. My thanks are due also to other members of the staff of the National Heart Hospital for their assistance in the selection and observation of cases.

REFERENCE

Balatre, P., Merlen, J. F., and Grandiean, L. (1949). Presse méd., 57, 1067. Bjerlov, H. (1942). Paper read at St. Mary's Hospital, Stockholm. - (1943). Svenska LäkT., 40, 694.

Dailheu-Geoffroy, P. (1950). Ouest med., 3, 37

Marche, J. (1950). Fich. méd., 144, 1.

Perlman, A (1952), Angiology, 3, 16.

Plotz, M. (1952). N.Y. St. J. Med., 52, 2012.

Samuels. S. S., and Padernacht, E. D. (1952). Angiology, 3, 20.

Talley, R. W., Beard, O. W., and Doherty, J. E. (1952). Amer. Heart J., 44, 866.

Van Oettingen, W. F., Donahue, D. D., Lawton, A. H., Monaco, A. R. Yagoda, H., and Valaer, P. J. (1944). U.S. Public Health Servic Bulletin. No. 282. Washington.

Winsor, T., and Humphreys, P. (1952). Angiology, 3, 1.

Zoll, P. M., and Norman, L. R. (1952). Circulation, 6, 832.

\section{APPENDICITIS IN THE COURSE OF MEASLES}

\section{BY \\ W. H. GALlOWAY, M.B., Ch.B., F.R.C.P.Ed. D.C.H. \\ Consultant Paediatrician}

(From the City Hospital, Aberdeen, and the Department of Child Health, University of Aberdeen)

Having personally seen seven cases of appendicitis occurring during the course of measles in the space of 18 months, I searched for any report on this matter in a British journal. No such report was found, except for a most interesting letter from Dr. Leak (1935). Several papers on this subject have been published in the German and American literature. In several standard works, gastro-intestinal lesions are described. Nothnagel (1902) discusses the pathology of individual organs as affected in measles as follows. "Although no anatomic changes are demonstrable in the intestines, the occurrence of frequent evacuations during an attack of measles bears a close relation to the underlying infectious process. Diarrhoea may appear as an early symptom, ushering in the enanthemic stage or even preceding it, but may also persist until after the conclusion of the eruptive stage. . . . The diarrhoea is ascribed to the specific inflammation of the intestinal mucous membrane, to the eruptive process by which it is affected."

In Modern Practice in Infectious Fevers (1951) lesions of the gastro-intestinal tract are described thus: "Inflammatory catarrh with desquamative changes extends the whole length of the digestive tract. Koplik spots may appear anywhere, including the vermiform appendix, which is often swollen and congested and may undergo suppurative or necrotic changes. Multinucleated giant cells may be found similar to those in the spleen, tonsils, and lymph glands."

Harries and Mitman (1951) also make reference: "Some observers have claimed that tenderness over the appendix region or a definite attack of appendicular colic is not infrequent during the prodromal stage of measles, and would correlate this occurrence with the demonstration of giant cells in the mucosa of the appendix. Laparotomy in such cases has revealed an appendix normal to the naked eye or showing catarrhal changes only. On the other hand, acute perforative appendicitis has occurred, probably as a fortuitous complication."

A brief description of seven cases is given below.

\section{Case Reports}

Case 1.-Male aged 4 years. History :-Two days before admission the child developed severe right-sided abdominal pain of colicky nature. He did not eat his evening meal. The attacks were spasmodic. He still had pain the next day On the day of admission he awoke screaming with rightsided pain, and occasionally drew up his legs. A loose stool was passed. There were no urinary symptoms. Examination:-Tenderness in right iliac fossa. P.R., marked tenderness on right side ; T. 99.2 (37.3 ${ }^{\circ}$ C.), P. 120 , R. 24. Operation:-Gridiron incision. Peritoneum healthy. Acutely inflamed pelvic appendix found and removed. Rash appeared four days after operation.

Case 2.-Male aged 11 years. History:-Four days before admission, developed cough and sore throat. Twenty-four hours before admission, measles rash appeared. Eight hours before admission, he awakened with colicky pain localized to the right iliac fossa; vomited once and passed a stool. Further pain two hours later. Examination:-Definite tenderness in right iliac fossa-localized. P.R. tender on the right ; T. $98.6\left(37^{\circ}\right.$ C.), P. 80, R. 22. Operation:-Gridiron incision; appendix showed slight redness. Rash appeared one day before admission.

Case 3.--Male aged 5 years. History:-Twelve hours before admission, while at school, he developed right-sided abdominal pain, not severe enough to make him leave. Pain became worse on way home and he vomited. Examination:-Tender in both iliac fossae. P.R., tender on both sides ; T. $98\left(36.7^{\circ}\right.$ C.), P. 112, R. 26. Operation :-Gridiron incision. Apparently healthy appendix-no fluid. One small gland felt. Appendix removed. Rash appeared four days after operation.

Case 4.-Male aged 5 years. History :-Forty-eight hours before admission, developed pain in right side and across lower abdomen ; colicky. Vomited twice. Examination :Tender in right iliac fossa with muscle-guarding. P.R., tender. Operation:-Gridiron incision. Slightly inflamed appendix removed. T. $99.4\left(37.4^{\circ}\right.$ C.), P. 96, R. 20. Rash appeared four days later.

Case 5.-Male aged 4 years. History :-Four days before admission, developed measles. Twelve hours before admission, onset of acute abdominal pain. Pain recurred eight hours later and he had a third spasm just before admission. Examination:-Well-marked measles rash. Abdomen held rigid. Definite tenderness in right iliac fossa. Operation :Gridiron incision. Perforated appendix with small quantity of purulent fluid in peritoneal cavity. Appendix removed. Rash appeared four days before admission.

Case 6.-Male aged $2 \frac{1}{2}$ years. History:-Three days before admission, complained of abdominal pain and vomited. Vaguely "out of sorts" for a day or two before this. Next day pain localized to right iliac fossa. Vomited three times. Fevered. Passed one loose stool. Observed overnight at Children's Hospital. Measles rash next morning. Transferred to City Hospital. Abdominal symptoms attributed to measles. Very definite signs of acute appendicitis, but operation postponed again because of the measles. T. $102.6\left(39.2^{\circ}\right.$ C. $)$, P. 160, R. 30 . By the next day the child had obvious peritonitis and a mass could be felt high in the right iliac fossa. Operation:-Gridiron incision. Purulent fluid in peritoneal cavity. Retrocaecal appendix with early abscess formation. Appendix removed and peritoneum drained. Rash in this case appeared two days before operation. The child developed pneumonia and died six days after operation.

Case 7.-Female aged 5 years 11 months. History:Abdominal pain four days before admission. Slight pain present next day, when child vomited on three occasions. 